\title{
ELEMENTOS ESTÁTICOS DA TEORIA POLÍTICA DE AUGUSTO COMTE: AS PÁTRIAS E O PODER TEMPORAL ${ }^{1}$
}

\author{
Gustavo Biscaia de Lacerda
}

\begin{abstract}
RESUMO
O presente artigo apresenta alguns dos elementos da teoria politica de Augusto Comte, dentro da sua Sociologia Estática, como componentes do que se poderia denominar sua teoria do Estado. Assim, após apresentar alguns dos pressupostos teóricos e metodológicos do fundador do Positivismo, o artigo concentra-se na exposição de suas teorias das pátrias e do Poder Temporal. Enquanto as pátrias constituem a base física da organização política, como resultante da união das famílias, nelas dando-se as relações de classe, o Poder Temporal é a própria função governativa, cujo âmbito de atuação é a ordem material da sociedade. Complementarmente ao Poder Temporal há o Poder Espiritual, responsável pela ordem intelectual e moral da sociedade, o que inclui a fiscalização e a legitimação do outro poder.
\end{abstract}

PALAVRAS-CHAVE: Augusto Comte; Positivismo; teoria política; pátrias; Poder Temporal; Poder Espiritual.

\section{INTRODUÇÃO}

Autor mais conhecido por suas elaborações filosóficas na área da ciência, Augusto Comte nascido Isidoro Augusto Maria Francisco Xavier Comte, em 1798 - pesquisou extensamente em Sociologia, inclusive no que atualmente denominamos Ciência Política. De modo mais específico, se considerarmos que "teoria do Estado" significa uma elaboração intelectual definindo os principais atributos do poder político em uma sociedade, estabelecendo suas relações com os diversos grupos sociais, suas funções e formas de atuação e de legitimação, além de sua de sua evolução ao longo do tempo - então, sem dúvida, Augusto Comte possui uma "teoria do Estado".

Como outros autores clássicos da Ciência Política ou da Sociologia, desde sempre Augusto Comte preocupou-se com a aplicação prática de suas elaborações, como recentemente lembrou Angèle

\footnotetext{
1 Agradeço aos pareceristas anônimos da Revista de Sociologia e Política por seus comentários e sugestões, assim como ao amigo Ângelo Torres, pelos extensos comentários que fez sobre este texto. Como de praxe, os eventuais problemas do artigo são de responsabilidade do autor.
}

Kremer Marietti (2003). Ocorre que, filósofo das ciências, tinha como preocupação também constituir a nascente Sociologia do mesmo estatuto epistemológico e "científico" que as demais ciências previamente constituídas, isto é, conjunto de proposições abstratas baseadas na observação de um tipo de fenômeno; além disso, exigia que fosse uma ciência geral da sociedade, isto é, aplicável a todas as sociedades, independentemente de local ou época - o que, por outro lado, impunha que todas as sociedades então conhecidas estivessem abrangidas por suas teorias. A conseqüência foi o caráter geral e "holístico" de suas observações, como condição para sua coerência teórica e sua eficácia prática. Nesse sentido, pode-se dizer que ele tem uma teoria geral sobre o Estado, talvez emulada apenas pela de Max Weber.

Dessa forma, o objetivo deste artigo é bastante simples: apresentar as concepções de Augusto Comte sobre o Estado; como veremos, todavia, para isso é necessária uma exposição prévia de alguns de seus pressupostos epistemológicos e teóricos. Embora, evidentemente, o interesse sempre seja o de apresentar com rapidez apenas os mínimos elementos necessários, face ao desconhecimento geral da obra de Comte requer-se que não sejam apenas "alguns" de seus pressupostos, mas "vários": "o pensamento de Augusto Comte tem 
uma forma tão sistemática que é praticamente impossível estudar com atenção um elemento se se ignora inteiramente a construção do conjunto"2 (LAUBIER, 1957, p. IX). Além disso, cumpre notar que seu estilo não é de fácil compreensão, pois mantinha seus escritos necessariamente abstratos, com uma linguagem característica e, preocupado com as aplicações práticas, a todo instante avaliava instituições, soluções propostas ao longo da história e alternativas ${ }^{3}$.

A perspectiva que adotamos aqui refere-se ao conjunto da obra de Augusto Comte, especialmente sobre as chamadas "obras de maturidade" 4 , na etapa final da vida do pensador, considerando-as integrantes de um sistema intelectual. Esses livros - justamente os menos conhecidos do público universitário e os mais importantes no conjunto da obra do autor - são os que reúnem o grosso de suas elaborações políticas, uma série dos quais não por acaso chama-se

2 Todas as citações cujos originais estão em língua estrangeira foram traduzidas livremente pelo autor.

3 Dessa forma, é importante que fique claro: apresentaremos aqui apenas as elaborações teóricas (isto é, abstratas) de Comte mais diretamente relacionadas ao que hoje chamaríamos de Estado; não pretendemos, portanto, sugerir uma "Ciência Política" a extrair-se de uma especialização do pensamento comteano. Da mesma forma, não pretendemos realizar uma comparação mais ou menos sistemática dessa obra com as elaborações mais recentes em Sociologia ou na Ciência Política: não por descurar desse tipo de investigação, mas porque não seriam cabíveis nos limites deste texto. A esse respeito, em todo caso, podese consultar com grande proveito Lopes (1946), Fletcher (1981), Torres (1997), Destefanis (2003), Lacerda Neto (2003) e Lacroix (2003).

${ }^{4}$ As obras de Augusto Comte organizam-se em três séries de escritos, além de vários opúsculos e o conjunto de sua correspondência e os chamados Opúsculos de filosofia social, de sua juventude. As séries de escritos são: Sistema de filosofia positiva, publicado entre 1830 e 1842, em seis volumes, avaliando filosoficamente o conjunto das ciências como constituíram-se até então, com vistas à fundação de uma nova, a Sociologia; Sistema de politica positiva, publicado entre 1851 e 1854, em quatro volumes, em que, fundada a Sociologia, procura aplicar os princípios anteriormente descobertos para a solução dos problemas sociais; Sintese subjetiva, que, prevista para ser em quatro volumes, acabou tendo apenas um, de 1856, em virtude do falecimento do autor; a meta da Síntese seria aplicar a algumas questões específicas, mas de altíssima importância (educação, organização econômica da sociedade), os princípios sociológicos.
Sistema de política positiva, publicados entre 1851 e 1854. Não nos interessa, portanto, realizar uma investigação sobre a evolução do pensamento do autor ao longo do tempo, isto é, uma pesquisa arqueológica.

\section{PRELIMINARES TEÓRICO-METODOLÓ- GICAS}

\section{II.1. A lei dos três estados e a classificação das ciências}

A "lei dos três estados" é a base de todo o sistema, pedra angular sem a qual não é possível compreender nem sua lógica nem seus objetivos. Seu enunciado final é o seguinte: "Cada entendimento oferece a sucessão dos três estados, fictício, abstrato e positivo, em relação às nossas concepções quaisquer, mas com uma velocidade proporcional à generalidade dos fenômenos correspondentes" (COMTE, 1934, p. 479). Em outras palavras, o ser humano pensa cada concepção e cada fenômeno de três formas sucessivas: primeiramente, fazendo referência a vontades exteriores ao fenômeno em questão. Essas vontades têm sedes muito claras, muito determinadas: em um processo de antropomorfização da realidade, o ser humano considera que seres dotados de sentimentos, pensamentos e atos semelhantes aos seus próprios atuam na realidade, provocando os fenômenos: são os deuses, e o modo de pensar é o teológico ${ }^{5}$. No enunciado acima, seria o modo fictício de pensar, por motivos evidentes.

Em seguida, o ser humano apela a abstrações, que, consideradas conscientemente como abstrações, são dotadas ainda de vontade: é a metafísica. Um autor que, sem se filiar ao Positivismo, percebeu com clareza o caráter da metafísica foi o historiador das relações internacionais JeanBaptiste Duroselle, como se percebe na citação abaixo: "Em nenhum campo, a reificação dos conceitos se passa tão facilmente quanto no domínio das forças, precisamente porque estas são visíveis apenas em seus efeitos. São designadas então por um nome anteriormente personalizado (Zeus para explicar o raio, Posídon para as ondas, Éolo para os ventos). Esse nome, em períodos mais

\footnotetext{
5 Na verdade, a teologia subdivide-se em outras quatro etapas, variando em função da quantidade e da generalidade das vontades na natureza, bem como da abstração dos raciocínios: o fetichismo, a astrolatria, o politeísmo e o monoteísmo.
} 
recentes, deixa de ser de uma pessoa mítica e tornase abstrato. Porém, antes que se encontre a explicação científica, o nome abstrato não é mais real que os deuses do Parnaso. E, portanto, dá-se a ele uma espécie de vida". E mais adiante: "E os que me dirão: realmente, o 'grande capital' não existe concretamente, porém 'tudo se passa como se' ele existisse, eu responderia que 'tudo se passa como se' é a própria fórmula pela qual se reificam os conceitos" (DUROSELLE, 2000, p. 34-35; grifos no original).

A citação acima indica com clareza como a metafísica surge da decomposição da teologia: são as mesmas preocupações, ao pesquisar os temas absolutos, e o mesmo método de raciocinar: apenas se substituem os deuses pelas abstrações. Por outro lado, é uma forma intermediária, pois conduz à positividade: assim, a metafísica, se trata dos mesmos problemas que a teologia e compartilha sua preocupação com o absoluto, já começa a investigar a realidade, lançando mão da observação direta dos fenômenos.

Finalmente, o estado positivo é aquele em que o ser humano abandona as pretensões absolutas, rendendo-se à evidência de que apenas percebe o relativo, da mesma forma que passa a subordinar a imaginação à observação dos fenômenos.

"Porque vinculava estreitamente a vida intelectual à vida social, Augusto Comte não podia separar seu projeto de sociedade de uma epistemologia fundamental. E, se projetou e realizou uma obra enciclopédica, é porque considerava os problemas políticos, sociais e culturais como estreitamente ligados à nossa capacidade de resolvê-los - sendo que essa capacidade era, ela mesma, política, social e cultural" (MARIETTI, 2003).

Assim, o modo de pensar, isto é, de perceber a realidade do mundo e do ser humano, determina e é determinado pela sociedade em questão. Relativamente ao modo positivo de pensar, essa íntima relação com a sociedade implica também que o objeto de preocupação do ser humano muda, das questões absolutas e teológicas no modo fictício de pensar, para o próprio ser humano e a realidade que o cerca, atento à relatividade do conhecimento: é dessa forma que a emancipação intelectual conduz o ser humano à preocupação consciente com os assuntos sociais, permitindo, além disso, um vigoroso humanismo (em um sentido forte dessa expressão).
Ora, o quadro apresentado acima corresponde apenas à sucessão dos três estados, o teológico, o metafísico e o positivo: resta comentar o " $[. .$.$] com$ uma velocidade proporcional à generalidade dos fenômenos correspondentes" (COMTE, 1934, p. 479). Esse enunciado indica que, quando mais simples for o fenômeno considerado, mais rapidamente ele passará da teologia à metafísica; inversamente, quando mais complicado for, mais demoradamente seguirá esse percurso. Daí Comte ter enunciado sua lei da classificação das ciências, complementar à dos três estados: em número de sete, as ciências são: a Matemática, a Astronomia, a Física, a Química, a Biologia, a Sociologia e a Moral. Essa seqüência indica um aumento de complexidade teórica, isto é, maiores dificuldades para apreenderem-se as variáveis intervenientes relevantes, relativas a cada um fenômenos específicos. Em outras palavras, para estudarmos a Astronomia, necessitamos de um instrumental matemático; a Física pressupõe o estudo da situação do planeta Terra no Universo; a Química pressupõe o conhecimento das propriedades da matéria, além de sua posição universal, para determinar a constituição dessa matéria; na seqüência, a Biologia supõe todas essas variáveis para avançar sobre os corpos vivos e, por sua vez, a Sociologia deve considerar todos os fenômenos anteriores para pesquisar como organiza-se um ser vivo em particular, cuja característica, aliás, é a associação. Por fim, a Moral pesquisa o ser humano individualmente $^{6}$, pressupostos todos os conhecimentos anteriores. Essa seqüência, ao mesmo tempo que lógica, é, portanto, também histórica, pois indica a ordem em que as diversas ciências (isto é, os vários corpos de teorias abstratas a respeito de fenômenos específicos) constituíram-se ao longo da história.

Vê-se, portanto, como a pesquisa da sociedade é uma das mais complexas, pois exige uma série imensa de conhecimentos prévios (que importam na forma das inúmeras variáveis cosmológicas), além, é claro, da observação dos próprios fenômenos humanos, sujeitos a leis próprias, observadas com instrumentos específicos da Sociologia.

Dessa forma, a constituição da Sociologia como ciência coroa um trajeto percorrido pelo ser humano, de preocupações externas à sua própria

\footnotetext{
6 No que seria denominada atualmente, portanto, simplesmente de "Psicologia".
} 
realidade a si mesmo. A Sociologia representa, portanto, um projeto intelectual e político, pois representa o ser humano chegando, afinal, à maturidade e assumindo sua própria vida ${ }^{7}$.

\section{II.2. Outros elementos teórico-metodológicos}

Vistas as duas formulações fundamentais de toda a obra comteana, podemos passar a algumas outras considerações preliminares, que aliás indicam o caráter de suas elaborações e sugerem algumas perspectivas que adiante apresentaremos.

A teoria sociológica comteana, ainda que formando um sistema coerente, do ponto de vista lógico divide-se em duas partes: a Sociologia Estática e a Sociologia Dinâmica. A primeira analisa os elementos permanentes da sociedade, aquelas instituições e aqueles fatos que em todas as sociedades existem, por mais variados que sejam ou pareçam. Os elementos da "ordem" são em número de cinco: a religião, o governo, a linguagem, a família e a propriedade. Por outro lado, a Sociologia Dinâmica concentra-se nas formas como as sociedades evoluem ao longo do tempo, ou seja, como os cinco elementos da Sociologia Estática desenvolvem-se. Aliás, a lei dos três estados, nesse sentido, é claramente uma lei da Sociologia Dinâmica, sua fundadora e seu primeiro resultado sistemático. Para nossos propósitos apenas a Sociologia Estática será considerada: a evolução do "governo" com o passar do tempo não terá nossa atenção aqui.

Por outro lado, a metodologia de Augusto Comte, como indicado acima, seria hoje denominada de "holística", por tomar o conjunto da sociedade como unidade analítica. Para ele, o indivíduo como unidade social é uma abstração sofística, "tão irracional quanto imoral", surgida com a desagregação do sistema social católicofeudal e até o momento em que escrevia - talvez

\footnotetext{
7 Eis uma declaração muito característica dessa vocação social de seu projeto, como indicado acima: “"Em nome do passado e do futuro, os servidores teóricos e os servidores práticos da Humanidade vêm tomar dignamente a direção geral dos negócios terrestres, para constituírem enfim a verdadeira providência, moral, intelectual e material, excluindo irrevogavelmente da supremacia política os diversos escravos de deus, católicos, protestantes ou deístas, como sendo, ao mesmo tempo, atrasados e perturbadores'. Tal foi a declaração decisiva com que terminei, no Palais Cardinal, no domingo 19 de outubro de 1851, meu terceiro Curso filosófico sobre a história geral da Humanidade" (COMTE, 1934, p. 1).
}

até ainda hoje - sem ser substituída por outro sistema social; na verdade, a unidade fundamental de análise em Sociologia deve ser a família. Além de indicar a anarquia mental, a ascensão do individualismo como suposta origem da sociedade - por exemplo, nas diversas obras contratualistas (Hobbes, Locke, Rousseau) - revela um desenvolvimento sistemático do egoísmo, erigido em padrão moral e intelectual, a despeito de preocupações com a sociedade como um todo. "Pegando o contrapé da ideologia metafísica própria aos philosophes das Luzes e inspirador das negações revolucionárias, Augusto Comte recusa-se a considerar o indivíduo como a unidade humana de base. Esse princípio egoísta parece-lhe igualmente errôneo em Biologia, em que o indivíduo não existe senão por e para a espécie, e em Sociologia, em que a célula fundamental é a família" (ARNAUD, 1965, p. 125).

Para nós o fato de Comte perceber a família como a verdadeira "célula social" é secundário; importa mais notar a negação do indivíduo como base lógica e real da sociedade, ao mesmo tempo em que a própria sociedade como um todo, em seus diversos níveis (família, pátria, Humanidade) ou não, é estudada. Na verdade, essa consideração pode ser generalizada como sendo, sempre, a primazia do espírito de conjunto sobre o de partes; no caso da sociologia, o espírito de conjunto não se refere apenas à percepção sincrônica, estática da sociedade: não importa somente perceber a sociedade como perfazendo um todo em um instante dado qualquer. Muito mais importante, porque definidor da própria sociedade humana - por ser sua característica específica-, é a consideração da historicidade humana: o que nos faz humanos é a possibilidade de uma geração somar-se a outra, desenvolvendo continuamente suas características. Assim, portanto, "[...] na pesquisa das leis sociais, o espírito deve indispensavelmente proceder do geral para o particular, isto é, começar por conceber, em seu conjunto, o desenvolvimento total da espécie humana, não distinguindo nele, a princípio, mais do que um número muito pequeno de estados sucessivos" (COMTE, 1972, p. 153).

É em virtude de sua historicidade que o ser humano pode, ao longo de sua evolução, desenvolver-se; é por esse motivo que a Sociologia Dinâmica não pesquisa apenas as condições do movimento e o próprio movimento das sociedades, como também, e talvez principalmente, a direção que a sociedade toma em seu desenvolvimento. 
Aliás, Comte seguia o passo de outros filósofos, pois, como: "Pascal e Fontenelle, como Comênio e Leibniz, insistiram sobre um tema de importância central: o sujeito cognoscitivo não é o indivíduo isolado, mas a humanidade inteira que progride no tempo. A humanidade, não esse ou aquele homem, tornou-se o protagonista efetivo do processo da história" (ROSSI, 1996, p. 74).

Outro elemento que cumpre uma função importante nas obras de Augusto Comte é sua concepção de natureza humana. Sendo a Humanidade um todo, tem ela, todavia, órgãos individuais, cuja base física tem uma tríplice característica, de sentimentos, de pensamentos e de atitudes práticas. Todas as instituições humanas visam a satisfazer, de alguma forma, essas características, mais ou menos isoladas umas das outras ou combinadas entre si. Além disso, por meio de uma refinada análise fisiológica, ele chegou à conclusão de que os sentimentos têm a primazia nas ações humanas, ou seja, os homens agem movidos por seus instintos afetivos; para tanto, a inteligência desperta-se, a fim de determinar os meios mais adequados para realizar os desideratos; com isso, evidentemente, o ser humano põe-se em ação, seja para investigar, seja para direta e propriamente agir: esse mecanismo foi sintetizado na frase: "Agir por afeição e pensar para agir", em que a "afeição" representa todos os sentimentos, altruístas e egoístas.

Para Augusto Comte, o ser humano possui dez instintos afetivos, sete egoístas e três altruístas, isto é, uns voltados para a conservação direta do próprio indivíduo e outros relativos ao relacionamento com outros: instintos nutritivo, sexual, materno, destruidor, construtivo, orgulho e vaidade, por um lado, e apego, veneração e bondade, por outro. Do primeiro para o último, a intensidade diminui, o que equivale a dizer que o ser humano é tanto "bom" quanto "mal", mas, principalmente, que o egoísmo é naturalmente mais forte, é naturalmente preponderante no ser humano. Em outras palavras: ainda que a humanidade seja principalmente a obra sucessiva das diversas gerações umas após as outras, os indivíduos entregues a si mesmos tendem (frise-se: tendem) a ser egoístas, isto é, a desconsiderar os demais. As instituições sociais, nesse sentido, existem, por um lado, para satisfazer as necessidades humanas e, por outro, para regular o egoísmo dos indivíduos. (Aliás: esse é, precisamente, o papel do governo nas sociedades.)

\section{PRIMEIRAAPROXIMAÇÃO: AS PÁTRIAS}

Ao tratarmos do tema "Estado", freqüentemente confundimos duas realidades que, a despeito de atualmente estarem estreitamente vinculadas, são, de fato, diferentes: o Estado-nação, ou seja, a forma de "Estado" que possui suas fronteiras bem definidas (pelo menos aspira a tal), exercendo, como diria Weber, o "monopólio do uso legítimo da violência física" sobre uma população que se mantém unida, em princípio, por um sentimento de comunidade étnica, religiosa, cultural ou uma mistura desses elementos. Assim, há dois elementos considerados: a associação das pessoas em um determinado território e o poder que sobre elas exerce o Estado. Para Augusto Comte essas são duas questões muitos diversas, embora, evidentemente, relacionadas, constituindo, por um lado, a teoria das pátrias e, por outro, a teoria do Poder Temporal. Nesta seção examinaremos apenas as pátrias e na seguinte, o Poder Temporal.

Cada indivíduo nasce no seio de uma família. Essa pequena unidade social, composta pelo casal, por seus filhos, por seus pais (isto é, pelos avós) e pelos agregados, tem como fundamento os sentimentos. Seu objetivo não é realizar nada de prático nem de filosofar ou de conhecer a realidade, mas, muito simplesmente, de manter juntas pessoas que mantêm diversos laços de afeto entre si, sendo um primeiro locus de socialização para cada um.

Ora, as diversas famílias reúnem-se com o objetivo de manterem-se materialmente: começa aí a pátria. Mesmo seu nome - "pátrias "-já indica a origem estreitamente vinculada às famílias. A pátria "[...] oferece um caráter essencial, que se desenvolve à medida que a instituição cresce" (COMTE, 1890b, p. 362): ela estabelece uma ligação entre o homem e seu meio ambiente natural, por intermédio da cooperação entre as diversas famílias.

As sociedades humanas têm uma característica importantíssima, mesmo fundamental: seus diversos órgãos, seus agentes variados podem escolher seus destinos, suas ações, optando ou não pelo concurso entre si, embora seja claro, por outro lado, que a sociedade como tal apenas pode existir na medida em que há, de fato, esse concurso: “[...] O caráter fundamental do grande organismo, como composto de seres suscetíveis de existir separadamente, mas concorrendo, mais ou menos 
voluntariamente, a um objetivo comum" (COMTE, 1890a, p. 293).

A passagem da associação familiar à cívica ocorre por meio da constituição das classes sociais (em algumas sociedades são as castas) - "O organismo coletivo permanece, então, essencialmente composto, primeiro pelas famílias que lhe constituem os verdadeiros elementos, então de classes ou castas que lhe formam seus próprios tecidos e enfim das cidades ou comunas, que são seus verdadeiros órgãos" (ibidem) - a partir do princípio aristotélico da "separação dos ofícios e convergência dos esforços", isto é, da divisão do trabalho social. A esse respeito, aliás, cumpre frisar que, ao contrário dos pensadores materialistas que, como indicou Dumont (2000), são todos aqueles que assumem um modelo economicista $\mathrm{e}$ individualista, ou seja, tanto os herdeiros do liberalismo quanto os marxistas - a concepção comteana de trabalho extrapola o mero trabalho físico, incluindo também o trabalho intelectual e - inovação completa - o trabalho moral e afetivo (LAGARRIGUE, 1920).

Se a vinculação entre os membros da família baseia-se nos afetos, a que ocorre nas pátrias vincula-se às necessidades comuns de seus membros, ou seja, visa à atividade prática, à modificação do ambiente com vistas à vida humana em cada sítio. Embora haja uma divisão do trabalho no seio das famílias, ela é bastante rudimentar e refere-se mais aos diferentes afetos que cada membro oferece aos demais. Nas pátrias - que Augusto Comte denominava também de "cidades" ("cités"), em uma clara alusão à Antiguidade e, até certo ponto, à Idade Média - ocorre plenamente a divisão do trabalho, cada indivíduo responsabilizado por um aspecto da vida comum - logo, a especialização é uma das características cívicas.

Da mesma forma, essa cooperação toma lugar em um conjunto minimamente grande de famílias, a fim de que a associação resultante não se pareça com uma simples extensão da unidade familiar. E, embora a cidade seja essencialmente prática, evidentemente é necessário que entre seus diversos membros deve existir laços afetivos, unindo todos em um destino comum, compartilhado muito mais a partir da convivência em um mesmo solo, cada qual realizando uma tarefa para o bem comum, que a partir da soma dos interesses particulares. Em outras palavras, há uma extensão dos sentimentos, que agora se desenvolvem e referem-se à pátria, composta por elementos de diversas procedências, atividades e, é claro, famílias.

"Após uma tal definição, a pátria adquire maior extensão à medida que o desenvolvimento humano habitua cada um a relações mais vastas. Tanto quanto dura nossa primeira infância, individual ou coletiva, ele permanece limitada à combinação entre a família e a casa, além dos quais nenhum vínculo pode ser suficientemente sentido. Essa restrição inicial corresponde à existência diretamente fundada sobre a afeição, sobretudo caracterizada pelo apego propriamente dito. Mas, ainda que o nome deva sempre depender dessa fonte, a instituição não se pode pronunciar senão além de uma extensão superior, sem a qual se confundiria a pátria com a simples família, espontaneamente inseparável do solo correspondente. A esse nível permanentemente afetivo deve suceder uma vida essencialmente ativa, que suscite habitualmente vínculos mais extensos, bastante restritos, todavia, para comportar uma suficiente intimidade após uma cooperação bastante sentida. Essas duas condições não são conciliáveis senão na existência cívica propriamente, a que se refere sempre a verdadeira instituição da pátria, em que a atividade combina-se com a veneração em relação a um lar inalterável. Mas, para que a instituição não degenere, a vida ativa deve ter um caráter necessariamente coletivo, sem o qual o concurso contínuo das famílias tornar-se-ia ilusório" "(COMTE, 1890 b, p. 362-363).

Realçamos: há a necessidade de uma cooperação prática entre as famílias, cuja origem é a separação dos ofícios, isto é, a especialização de cada uma em gênero de trabalho. É essa cooperação, aliás, que verdadeiramente distingue a cidade das famílias, cuja base, como indicamos acima, é a afeição comum entre seus membros. Comte tira uma conseqüência muito interessante e muito importante dessa característica fundamental das pátrias: "Nada faz sentir melhor

\footnotetext{
8 Além disso, o filósofo francês estipulava uma limitação no tamanho das diversas pátrias a países com a extensão máxima do que têm, atualmente, Portugal, Bélgica e países igualmente de pequenas proporções; sua justificativa era manter um nível de afetividade mínimo entre os diversos cidadãos, de modo a desenvolver o sentimento de cooperação e dependência mútuos. Assim, além dos países de dimensões continentais - entre os quais se inclui, evidentemente, o Brasil -, a pretensão por séculos acalentada de "império universal" é condenada (COMTE, 1934, p. 118, 356).
} 
como são profundamente anárquicas todas as teorias dos revolucionários modernos, que não consagram senão o puro individualismo, ao disporem-se a tudo nivelar" (COMTE, 1890a, p. 293), isto é, o individualismo moderno, ao negar as diferenças entre os grupos sociais, põe em xeque a própria condição de existência da sociedade. Além disso, é evidente que a nivelação a que o francês refere-se é a "igualdade" por que se batem os pensadores soi disant progressistas ${ }^{9}$...

Indicamos no início desta seção que, ao invés de tratarmos de uma versão comteana do conceito de "Estado-nação", abordaríamos as noções de pátria e em seguida da de Poder Temporal. Pois bem: sobre o que se comumente se chama de "estados", no sentido mesmo de "Estado-nação", Augusto Comte observa que ao longo da história percebem-se inúmeras associações assim chamadas (de "Estado"), limitadas por sua duração ou por sua extensão. Todavia, como a preocupação de sua pesquisa é com a história da Humanidade como um todo e como visa a estabelecer uma ciência abstrata geral, essas diversas associações particulares não têm lugar, da forma como apresentam-se empiricamente, podendo perfeitamente caber nos conceitos de "pátria" (e de "Poder Temporal", como veremos em seguida). Além disso, há uma série de instâncias intermediárias, cujos nomes, aliás, variam de maneira "quase arbitrária" - nações, províncias etc. - que dificultam a análise (idem, p. 290-291).

Da mesma forma, talvez caiba aqui o esclarecimento, prévio, da relação entre as pátrias e o Poder Temporal: enquanto aquelas são os órgãos da Humanidade, este realiza uma função, característica desses órgãos em particular - em outras palavras, aquelas são as sedes físicas onde opera este atributo (determinado, nesse sentido, abstratamente) ${ }^{10}$.

\section{O PODER TEMPORAL}

Como dissemos há pouco, as pátrias constituem a sede física onde opera concreta-

9 Augusto Comte não hesita em reconhecer que essa especialização é "fonte contínua de diversidade e mesmo de desigualdade" (COMTE, 1890a, p. 294; sem grifo no original).

10 Como se viu em citações anteriores, Augusto Comte lançava mão de metáforas biológicas para explicar a importância relativa das instituições sociais entre si: a família é a célula social, as classes (e as castas) são os mente a Humanidade em termos propriamente políticos: mas é análise que Augusto Comte desenvolve sobre o Poder Temporal que reside o "núcleo duro" de sua teoria política, isto é, de sua teoria do poder político. É nela que percebemos os temas clássicos das diversas teorias do Estado e do poder: o uso da força física, o problema da legitimação, os limites a que o poder sujeita-se, o papel do Estado na sociedade.

Se as pátrias, ou cidades, constituem por assim dizer a base física da sociabilidade humana, o espaço em que cada um relacionar-se-á com os demais e desempenhará seu papel como cidadão, ocorre, por outro lado, um fato importante: conseqüência da especialização contínua e necessária da sociedade, as vistas de conjunto - isto é, de destino e de causa comum -, vão-se perdendo: os diversos órgãos da Humanidade preocupam-se cada vez menos com os demais e concentram-se cada vez mais em si mesmos e nos seus interesses, deixando de lado a sociabilidade e o altruísmo e tornando-se cada vez mais egoístas.

O resultado é a necessidade de um órgão coletivo que mantenha a união da sociedade, evitando a desagregação, ao mesmo tempo que coordenando os esforços parciais: esse órgão é, evidentemente, o governo. Assim como aparece na obra de divulgação que é o Catecismo positivista, no sistema de Comte, o governo exerce uma função primordial, não sendo possível nenhuma sociedade sem ele: "Com efeito, cada servidor da Humanidade deve sempre ser apreciado sob dois aspectos distintos embora simultâneos, primeiro em relação ao seu ofício especial, depois quanto à harmonia geral. O primeiro dever de todo órgão social consiste, sem dúvida, em bem preencher sua própria função. Mas a boa ordem exige também que cada um assista, tanto quanto possível, a realização dos outros ofícios quaisquer. Semelhante atributo torna-se mesmo o caráter principal do

tecidos, as cidades são os órgãos, a Humanidade é o organismo. Levando adiante essa metáfora, ele considerava que, havendo cinco graus de organização na Fisiologia, a Sociologia poderia também adotá-los, faltando aí o nível dos aparelhos e dos sistemas, eventualmente o reservando para as instituições e relações que ligam - e ligarão - entre si as diversas partes da Humanidade, isto é, as cidades e os países entre si: relações econômicas, culturais, intelectuais, afetivas etc. De qualquer maneira, o autor tinha bastante claro serem apenas metáforas biológicas, cuja eficácia teórica não se pode exagerar (COMTE, 1890a, p. 292-293). 
organismo coletivo, em virtude da natureza inteligente e livre de todos os seus agentes.

Ora, existe espontaneamente uma oposição cada vez mais pronunciada entre estes dois ofícios, um especial, outro geral, de cada funcionário humano. Porquanto, o primeiro particularizandose mais à medida que a cooperação se desenvolve, suscita disposições intelectuais e mesmo tendências morais, que afastam cada vez mais de uma apreciação de conjunto, que também vai se tornando cada vez mais difícil. Tal é o verdadeiro ponto de vista elementar da teoria geral do governo, primeiro temporal, depois espiritual.

Como nenhuma função, mesmo vital, e sobretudo social, pode ser bem preenchida senão por meio de um órgão próprio, o mínimo concurso humano exige, pois, uma força especialmente destinada a chamar de novo às vistas e aos sentimentos de conjunto agentes que tendem sempre a desviar-se de tais condições. Ela deve sem cessar conter as suas divergências e desenvolver as suas convergências. Por outro lado, este poder indispensável surge naturalmente das desigualdades que suscita a evolução humana.

Apesar da íntima simpatia que constitui a simples associação doméstica, mesmo reduzida ao par fundamental, não está ela nunca isenta de semelhante necessidade. É aí que se pode apreciar melhor este grande axioma: Não existe sociedade sem governo" (COMTE, 1934, p. 293-295; grifos no original).

A análise acima é de teor funcionalista: o governo possui uma função a realizar na sociedade e é por esse meio que Augusto Comte explica a origem e o propósito do governo. Todavia, não é o preenchimento de sua função que confere legitimidade ao governo, cabível a outro órgão, que possui ainda outros papéis: essa é a base da divisão dos poderes no sistema comteano, o Poder Temporal e o Poder Espiritual.

Importa desde já notar que a separação dos dois poderes é uma característica moderna, esboçada na Idade Média. Na Antigüidade o politeísmo confundia o Poder Temporal com o Poder Espiritual, dominando um ao outro; assim, a sociedade era militar - e o chefe guerreiro era também um sacerdote - ou era sacerdotal - e a atividade tendia a ser pacífica. Em tanto um quanto no outro caso, o órgão que mantinha a ordem civil também era responsável pela difusão dos valores que manti- nham as sociedades unidas, das teorias interpretativas e explicativas da realidade e, finalmente, dos princípios de legitimação da ordem social existente. Modernamente, por outro lado, a separação dos dois poderes é tanto inevitável, em virtude do desenvolvimento das capacidades humanas e das especialização de funções, quanto indispensável, a fim de garantir as mais diversas liberdades e permitir o advento do Positivismo como força social por meio do livre convencimento (COMTE, 1890b, p. 199-200; LACERDA, 2003; LACERDA NETO, 2003).

Também percebidos por Augusto Comte como os órgãos de reação do conjunto da sociedade sobre as suas diversas partes, os poderes têm origens diversas e, atuando sobre a sociedade a partir de diferentes posições, têm funções diversas. Como a natureza humana é tríplice, três são os poderes sociais: o material, o intelectual e o afetivo. O poder material concentra-se na força física ou na riqueza; o poder intelectual cabe aos filósofos e aos sacerdotes, enquanto o poder afetivo cabe às mulheres. Ora, considerando, por um lado, a eficácia prática do poder material e sua preponderância sobre os outros dois, e, por outro, a atuação de aconselhamento e direção que os outros dois têm sobre o primeiro, eles constituem-se em dois grandes: o primeiro é o Poder Temporal, responsável pela manutenção física da sociedade, e o Poder Espiritual, que mantém os valores sociais e, especialmente, orienta e aconselha, isto é, modifica o Poder Temporal (COMTE, 1890a, p. 311).

Augusto Comte não tinha como preocupação definir o que seja o "poder", ao menos não com o refinamento que assumiram várias definições no século XX, especialmente pela Ciência Política norte-americana a partir da sugestão de Max Weber, segundo a qual o "poder significa a probabilidade de impor a própria vontade, dentro de uma relação social, ainda que contra toda resistência e qualquer que seja o fundamento dessa probabilidade" (WEBER, 1997, p. 43; grifo no original), isto é, como uma relação entre agentes, em que um consegue, por quaisquer meios à sua disposição, fazer que um outro, mesmo a contragosto, aja como o primeiro deseja.

No dicionário elaborado por Ângelo Torres, assim, a definição de poder que aparece é a seguinte: "É o governo, indispensável à sociedade. Há sempre o poder teórico ou espiritual e o poder ma- 
terial, separados ou unidos. Não há sociedade sem governo" (TORRES, 1997, p. 96); no dicionário de Bourdet (1875) nada aparece. Conforme transparece no resumo de Torres, a ênfase cai no governo, seja no material, do Poder Temporal, seja no teórico, do Poder Espiritual. Além disso, pelo que indicamos um pouco mais acima de Augusto Comte, cada classe social tem seu próprio tipo de poder, cujos campos de atuação já se esboça: o poder material tem eficácia prática, isto é, sobre as coisas, sobre a realidade material, sobre o mundo, em outras palavras, por uma via direta; o poder espiritual age modificando a conduta do poder temporal, isto é, atua sobre os indivíduos, aconselhando, ensinando, sugerindo - indiretamente, portanto.

Uma outra passagem, agora diretamente do Sistema de política positiva, apresenta outras noções de interesse: "A necessidade de concurso, inseparável da de independência, exige então, assim, sua própria satisfação permanente, após uma instituição fundamental convenientemente adaptada a esse fim necessário. Ela torna-se a nós tão mais indispensável quanto os instintos que nos conduzem ao isolamento ou aos conflitos são naturalmente mais enérgicos que os que nos dispõem à concórdia. Ora, tal é a destinação geral própria à força de coesão social designada em todos os lugares sob o nome de governo, que ao mesmo tempo conter e dirigir. A admirável concepção de Aristóteles ${ }^{11}$ institui então uma luminosa combinação entre os dois elementos necessários de todo pensamento político, a sociedade e o governo" (COMTE, 1890a, p. 294-295).

Por um lado, justifica-se a necessidade do governo indicando-se sua origem lógica: como a sociedade exige a cooperação mas o ser humano naturalmente tende ao individualismo, isto é, a cessar a cooperação, é necessário um órgão que mantenha todos cooperando entre si. Por outro lado, define-se uma função geral para o governo, dentro de um esquema funcionalista: ao mesmo

\footnotetext{
11 Segundo a qual a essência da sociedade consiste na separação dos ofícios e na convergência dos esforços. Conforme indica Miguel Lemos em sua tradução do Catecismo positivista, não há, nas obras do estagirita, nenhuma passagem com essa formulação: Augusto Comte, ao lê-las, concluiu poder extrair esse princípio, reconhecendo, de qualquer forma, sua autoria como sendo do pensador grego.
}

tempo ele deve conter aqueles elementos que se afastam do esforço coletivo e dirigir os esforços daqueles que se empenham em prol da sociedade. Também fica bastante claro que o poder exige dois elementos relacionados para existir, um que aplica e outro sobre quem se aplica. Por fim, embora se pense basicamente no poder político - "material" ou "temporal", na terminologia de Augusto Comte - há claramente a possibilidade de estendê-lo ao Poder Espiritual.

Mais particularmente, o Poder Temporal deve expandir-se por toda a sociedade, isto é, deve ser capaz de atingir todas as porções sociais, a fim de manter a coesão social e dirigi-la. O meio específico de atuação é - isso é importante ressaltar - a força: "A obrigação especial e o comando parcial não devem, então, senão se generalizarem convenientemente, para constituir, sem grandes obstáculos, uma força de coesão capaz, dentre de todo Estado, de conter as divergências e de dirigir as convergências.

É assim que o princípio da cooperação apenas, sobre o qual repousa a sociedade política propriamente dita, suscite naturalmente o governo, que deve mantê-la e dirigi-la. Uma tal potência apresenta-se, na verdade, como essencialmente material, pois resulta sempre da grandeza ou da riqueza. Mas importa reconhecer que a ordem social não pode jamais ter outra base imediata. O célebre princípio de Hobbes sobre a dominação espontânea da força constitui, no fundo, o único passo capital que ainda se deu, de Aristóteles até mim, na teoria positiva do governo" (idem, p. 298-299).

A passagem acima suscita dois comentários. O primeiro é, evidentemente, relativo ao fundamento último do poder, baseado em Hobbes e seguindo a tradição realista do pensamento político: o que o mantém é a força, a violência. Embora, como notou Raymond Aron (1999, p. 110), essa observação possa chocar um leitor de Augusto Comte, não é possível ser de outra maneira, sendo a natureza humana como é - como veremos mais abaixo. Em todo caso, Comte não deixou de ironizar aqueles que consideram que o Poder Temporal não deve ser capaz de agir, isto é, que não deve ser, de fato, um "poder": "Todos aqueles que se chocam com a proposição de Hobbes achariam estranho, sem dúvida, que em lugar de fazer repousar a ordem política sobre a força, quiséssemos estabelecê-la sobre a fraqueza" (COMTE, 1890a, p. 299). 
A segunda observação é a seguinte. Como já indicamos anteriormente, o fundamento do Poder Temporal pode ser tanto a "grandeza" - a força física, pura e simplesmente - quanto a riqueza, isto é, o que chamamos atualmente de "poder econômico". Ao contrário do pensamento político do século XX (BOBBIO, 1997, p. 110), Augusto Comte não separava o poder político do econômico: na verdade, considerando que as sociedades humanas ao longo de suas histórias passam de atividades guerreiras, baseadas, por óbvio, na violência, para atividades industriais, pacíficas, ele postulava que tendencialmente o poder político, de mando, deveria ficar nas mãos de industriais, ou do poder econômico, como diríamos hoje ${ }^{12}$. Nesse caso, ainda que sem descartar o uso da violência física em casos extremos (por meio da polícia ou até da pena de morte - embora defendendo o fim dos exércitos), o "poder de coesão" que o conjunto da sociedade exerceria sobre seus diversos órgãos dar-se-ia por via das pressões econômicas ${ }^{13}$.

Ora, o mesmo poder que tem por função manter a coesão social pode desviar-se de seus fins, tornando-se demasiado ou sendo aplicado em fins incorretos. Além disso, a força não pode pura e simplesmente ser aplicada, isto é, ainda que a força como tal justifique-se como fundamento do Poder Temporal, ela apenas não basta, havendo a necessidade de uma sanção emitida por outro órgão: em outras palavras, há a necessidade de legitimação do poder. "Pero aunque la fuerza es el fundamento indispensable de toda organización de la sociedad, debemos recordar que por símisma es totalmente insuficiente. La fuerza siempre requiere el complemento doble del intelecto y el

12 Lacerda Neto (2003) apresenta detalhadamente o projeto político de Augusto Comte, após repassar os fundamentos epistemológicos e históricos de suas concepções, indicando como o filósofo francês pretendia que se organizasse a sociedade em uma época de paz generalizada, fraternidade universal e um conhecimento positivo da realidade do mundo e do ser humano.

13 Face aos problemas que a "sociedade industrial" notoriamente apresenta, especialmente em termos de conflitos de classe, importa indicar a seguinte observação de Comte: "Mesmo hoje, a vida industrial não suscita senão classes imperfeitamente ligadas entre si, à falta de um impulso assaz geral para tudo coordenar sem nada atrapalhar; esse é o principal problema da civilização moderna"(COMTE, 1890b, p. 363; sem grifos no original). corazón, y fomenta una influencia controladora adecuada, para volverla la base durable de la autoridad política" (COMTE, 1995, p. 218; sem grifos no original). Assim, o Poder Temporal pode, em casos extremos, obrigar os diversos órgãos a considerar o bem comum: o que importa, porém, é que tais órgãos o mais livre e espontaneamente possível assintam com essa consideração. O órgão responsável ao mesmo temo pela fiscalização, pela sanção e pela moderação do Poder Temporal é o Poder Espiritual, cujo meio de atuação é o aconselhamento e a sugestão.

Indicamos mais acima que o Poder Espiritual atua por via indireta: sua potência refere-se à capacidade de convencer e mudar o comportamento dos indivíduos pelo assentimento às suas observações. Nesse sentido, o "Poder Espiritual" não se encaixaria na definição weberiana de poder - ao menos não totalmente -, pois é-lhe vedado "[...] impor a própria vontade $[\ldots]$ ainda que contra toda resistência [...]" (WEBER, 1997, p. 43).

A condição de funcionamento de tal exigência é uma única, muito simples de enunciar, tanto quanto freqüentemente difícil de realizar: nas sociedades contemporâneas deve ocorrer a completa separação entre os dois poderes. Em outras palavras, o Poder Espiritual não pode mandar e o Poder Temporal não pode "opinar". Este deve apenas manter a ordem pública eventualmente auxiliando no desenvolvimento material da sociedade - e aquele deve constituir as teorias e as doutrinas gerais que orientam a sociedade, além de - e isto é de central importância -, pela associação entre os filósofos e sacerdotes, por um lado, e os proletários e as mulheres, por outro, constituir uma opinião pública, cujo papel é, precisamente, fiscalizar a atuação do Poder Temporal, orientando sua conduta e condenando seus excessos (ou faltas).

Ainda que o objetivo deste artigo seja apenas o de comentar os elementos da teoria sociológica de Augusto Comte que se referem à organização estritamente política da sociedade, não é possível fazer qualquer referência ao Poder Temporal sem indicar suas íntimas e complexas relações com o Poder Espiritual. A importância que Augusto Comte atribuía ao último e a insistência com que assinalou seu papel na sociedade já o distingue da maior parte dos pensadores políticos - o que é curioso, pois, ao mesmo tempo em que se filia à tradição realista do pensamento político, também 
se filia a uma "tradição" "idealista", geralmente representada por Immanuel Kant ${ }^{14}$. Na verdade, como diria nas obras da maturidade, todos seus esforços foram no sentido de constituir um novo Poder Espiritual, substituto da decaída e há muito retrógrada Igreja Católica, adequado ao período crescentemente positivo da Humanidade, capaz de "reorganizar a sociedade sem deus nem rei", como anunciava desde seus opúsculos de juventude (COMTE, 1972).

O Poder Espiritual, se comparado ao Temporal, seria ao mesmo tempo relativo ao espírito e permanente; seria o poder teórico, em relação ao qual o outro seria o prático e seria o poder geral, relativo a todos os povos, a partir de uma educação comum, em contraste com a particularidade do outro. Assim, o Poder Espiritual, fundamentalmente teórico, tem como objetivo elaborar, a partir dos principais resultados científicos, as concepções gerais sobre a realidade, cosmológica e humana, constituindo uma opinião pública capaz de desenvolver e apoiar as instituições que essas mesmas concepções gerais, de teor científico, sugerem. Nesse sentido, o Poder Espiritual consiste tanto em um órgão que elaborará um sistema de educação quanto o aplicará. Para tanto, os conhecimentos parciais e analíticos elaborados pela ciência seriam coordenados em uma síntese, caracterizada necessariamente pela perspectiva humana e pelas vistas de conjunto ${ }^{15}$.

O Poder Espiritual ainda possui um âmbito de atuação maior que o Poder Temporal, por si só

\footnotetext{
14 Continuando com as referências aos filósofos modernos, a combinação originalíssima das idéias de Hobbes e Kant lembra a fílosofia de Hugo Grócio. Embora não tenha sofrido uma grande influência desse pensador - as referências fundamentais do pensamento comteano são Condorcet, David Hume, Diderot e Joseph de Maistre Augusto Comte reconheceu-lhe a importância, incluindoo mesmo em seu "Calendário positivista concreto". Nas teorias de política internacional, a original posição "intermediária" de Augusto Comte em relação a Hobbes (realismo) e a Kant (idealismo) emparelham-no, não por acaso, com a tradição grociana, representada no século XX pelos ingleses Martin Wight e Hedley Bull.

15 Aliás, Comte indica que "com a descoberta das leis sociológicas, uma síntese baseada na Ciência torna-se possível, a Ciência agora concentrando-se no estudo da Humanidade" (COMTE, 1957, p. 366). Como se vê, o projeto comteano é um humanismo no sentido forte e rigoroso da expressão, valorizando profundamente o ser humano e tomando-o de fato como "a medida de todas as coisas".
}

restrito: "Na ordem cívica, cada concurso de famílias para um fim determinado faz em breve surgir um chefe prático, cuja autoridade se acha espontaneamente limitada pelo conjunto das operações que ele pode realmente dirigir, quer pela sua própria aptidão, quer sobretudo em virtude de seus capitais. É aí que reside o verdadeiro poder temporal, igualmente capaz de impulsar e de reter, conforme as necessidades. Todo poder mais vasto dimana necessariamente de uma fonte espiritual" (COMTE, 1934, p. 295; sem grifos no original). Essa fonte espiritual faria prevalecer as vistas de conjunto - que, no sistema comteano, assume uma perspectiva sincrônica e principalmente diacrônica, ou, em seus próprios termos, a continuidade é mais enfatizada que a solidariedade ${ }^{16}$ (sem prejuízo desta, claro está).

"Após ter suficientemente oposto a generalidade característica do poder espiritual à especificidade necessária do Poder Temporal, não falta senão completar seu contraste fundamental por uma diferença diretamente conexa com a precedente. Ela concerne ao seu domínio territorial, universal para o primeiro e sempre parcial relação ao segundo. Cultivando a arte geral, apenas igualmente indispensável em todas as partes, o sacerdote pode e deve espalhar seu ofício a todas as porções do planeta humano, quando sua doutrina fundamental tornar-se assaz real e assaz completa para prevalecer uniformemente. Ao contrário, o poder material, destinado sobretudo a regular as operações especiais e locais, não saberá dominar sem opressão senão um território determinado, bem menos estendido mesmo que como cremos hoje. Os diversos vínculos habituais que esses trabalhos parciais estabelecem espontaneamente entre todas as regiões terrestres não comporta mais senão que não exige nenhuma concentração sistemática. Não é jamais a força, mas a sabedoria, o que deve por toda parte fazer prevalecer livremente as instituições práticas sem as quais as relações contínuas não adquirirão a

\footnotetext{
16 A importância da noção de continuidade histórica não deve ser subestimada. Mesmo com os preconceitos revolucionários característicos do marxismo e do comunismo (COMTE, 1957, p. 178; 1997, p. 292), o historiador egípcio Eric Hobsbawm comentou há alguns anos que "A memória histórica já não est[á] viva. [...] Quase todos os jovens de hoje crescem numa espécie de presente contínuo, sem qualquer relação orgânica com o passado público da época em que vivem" (HOBSBAWM, 1999, p. 13).
} 
uniformidade desejável. Mantém-se a mesma coisa para as iniciativas temporárias que demandem um concurso especial entre diversos governos" (COMTE, 1890a, p. 319-320).

O comentário acima, além de realçar o caráter potencialmente universal do Poder Espiritual, reforça o caráter necessariamente local do Poder Temporal, vedando-lhe extensões territoriais muito amplas. Ora, isso é uma outra forma de exprimir a necessária limitação dos ajuntamentos políticos, justificando a extensão das pátrias a tamanhos bem menores do que hoje acontecem - Comte sugeria que os países terão área semelhante à Bélgica, a Portugal, à Holanda etc. --, condenando, no limite, as pretensões de "império universal": a única forma de congregar todos os seres humanos é por meio do espírito, mantido pelo Poder Espiritual.

A separação entre os dois poderes corresponde àquela mais geral, entre a teoria e a prática. Separar a teoria da prática tem como objetivo e resultado principal estabelecer uma classe de homens que se dedicam exclusivamente à reflexão e à contemplação ${ }^{17}$ da realidade, ao mesmo tempo cosmológica e humana. Os princípios obtidos pelo Poder Espiritual, baseados na observação científica tanto do mundo em geral quanto da sociedade e do ser humano, devem ser vistos como orientadores da atividade política, não devendo ser aplicados diretamente - pois não se prestam a tal. Assim, da mesma forma que a Astronomia auxiliava - e ainda auxilia - a arte da navegação, ou que a Física auxilia a Engenharia, ou que a Biologia ilumina e orienta a Medicina, a Sociologia deve iluminar e orientar a atividade política. Insistimos: o Poder Espiritual consiste em uma categoria de homens especialmente dedicados à contemplação da realidade: Augusto Comte em inúmeras vezes deixou claro que simplesmente lhes vedava a participação na política prática, a fim de assegurar sua independência e, portanto, o cumprimento de seu papel social. "A primeira condição da autoridade espiritual é a exclusão do poder político, como uma garantia de que a teoria e a prática manter-se-ão sistematicamente separadas. Um sistema em que os órgãos do

17 Claro está que "contemplação" não possui aqui um sentido quietista, referindo-se, antes, à não "intervenção" na realidade com vistas à sua alteração: intervém-se nela, mas apenas para conhecê-la. conselho e os do comando nunca são idênticos não pode, quiçá, degenerar em qualquer dos malefícios da teocracia" (COMTE, 1957, p. 367), isto é, no imobilismo, na opressão e na falta de liberdade. Da mesma forma, a verdadeira separação entre os dois poderes é o que garante ao mesmo tempo que o Poder Espiritual não se corromperá, tornando-se servil ao Poder Temporal, e que o regime político não seja, como geralmente se pretende a respeito do projeto político do Positivismo, uma tecnocracia.

Por outro lado, Augusto Comte percebia que a mais importante garantia que um regime tem para ser livre ("liberal", como define Sartori (1994, cap. 13)) é a separação entre dois poderes, agora relativamente ao Poder Temporal: o Estado não pode esposar nem patrocinar qualquer doutrina, devendo tão-somente cuidar dos aspectos materiais da sociedade. O papel de condução mais geral dos rumos sociais, a partir de uma influência sempre indireta, por meio da opinião pública, bem como a mais ampla possibilidade de crítica à ação governamental, cabe ao Poder Espiritual, ou seja, aos filósofos, pensadores, jornalistas, artistas e todos aqueles que se ocupam do "espírito"; de qualquer forma, é completamente vedado ao Estado a intromissão nesses assuntos - aí se incluindo, por óbvio, a manipulação dos meios de comunicação.

Se o Poder Espiritual, ao submeter-se ao Temporal, pode tornar-se servil, ou seja, corrupto, ao controlar o comando político torna-se opressor, pois impassível de crítica. "Assim, voltada a guiar somente a atividade, renuncia a ditadura republicana a qualquer interferência opinativa, quer impondo convicções, quer coibindo-as. Cabe-lhe manter energicamente a ordem material da sociedade [...], respeitando escrupulosamente seu movimento intelectual - opinativo -, por mais desregrado que se torne ele. Logo: plena liberdade de discussão e de exposição, como garantia inarredável contra a sempre iminente degeneração da ditadura em tirania, aquisição a manter-se em caráter nada menos que definitivo" (LACERDA NETO, 2003, p. 84 et passim; sem grifos no original).

Dessa forma, em se tratando da liberdade de pensamento e de expressão, ou, por outra, do não cerceamento, da parte do Estado ou do governo, das liberdades civis e também das dos meios de comunicação, a elaboração de Augusto Comte ofe- 
rece uma importante fundamentação. Mais particularmente, embora careça de uma investigação específica, parece-nos que o único pensador a considerar que a garantia fundamental e principal das liberdades em um regime de liberdade é precisamente o caráter intocável dos meios de comunicação pelo governo ou pelo Estado foi Augusto Comte ${ }^{18}$.

Cabem aqui algumas precisões. A primeira é que, ao tratar-se da "liberdade de expressão", pressupõe-se a liberdade de pensamento e também a de culto: só faz sentido alguém reivindicar a possibilidade de dizer o que quiser se puder, antes, pensar o que quiser; invertendo essa relação, também se pode considerar que quem quer falar alguma coisa já pode, de antemão (ou ao mesmo tempo), pensar e acreditar no que quiser.

Em segundo lugar, Comte indica a liberdade de expressão como uma capacidade ativa: os indivíduos dispõem dela e realmente a utilizam, advindo precisamente daí, de seu caráter atual, todas as suas virtudes, intelectuais, morais, sociais e políticas. Um regime em que haja apenas nominalmente a liberdade de expressão e de pensamento é um regime condenado ao fracasso.

Por fim, a questão teórica relativa à preponderância de um poder sobre o outro; essa questão, aliás, se é teórica e avança para conseqüências práticas, também recua, considerando alguns fundamentos epistemológicos do Positivismo: "Nós reconhecemos que todo homem pertence ao mesmo tempo, pelo sentimento, a uma família determinada, pela atividade, a uma certa cidade, e pela inteligência, a alguma Igreja. Estudando simplesmente a estrutura, é supérfluo examinar qual dessas três sociedades simultâneas deva prevalecer. Mas não saberíamos apreciar claramente a existência sem ter previamente estabelecido sua subordinação natural. É necessário então decidir agora a questão abstrata da preponderância normal entre a sociedade doméstica, a sociedade civil ou política e a sociedade religiosa.

Ora, essa determinação preliminar resulta espontaneamente da teoria fundamental da natureza humana, que, subordinando a existência

18 Nesse sentido, sua contribuição para as teorias da democracia em geral, e relativamente aos meios de comunicação (MIGUEL, 2000) em particular, ainda completamente inexplorada, seria enorme. cerebral à existência corporal, faz prevalecer sempre a atividade sobre a inteligência e mesmo sobre o sentimento. É então à cidade, órgão essencial da cooperação ativa, que se deve sobretudo voltar-se o homem, mas conservandoa sem cessar como preparada pela família e completada pela Igreja. Ainda que a sociedade política seja necessariamente composta por sociedades domésticas, a primeira determina somente o conjunto da existência própria a cada uma das outras, após a repartição geral dos trabalhos humanos, que domina em todos os lugares seus destinos respectivos. Irrecusável desde o primeiro ensaio de nossa civilização, essa preponderância normal torna-se cada vez mais pronunciada, à medida que se desenvolve nossa solidariedade e nossa continuidade. Assim o instinto universal confirma essencialmente uma tal subordinação, que em todos os lugares dispõe a conceber habitualmente o homem como cidadão.

Mas essa primeira apreciação parece não deixar nenhuma dúvida sobre a segunda parte da questão precedente. Assim, se o sentimento mesmo subordina-se à atividade, como a inteligência poderia dispensá- la? [...]

A religião positiva, em virtude de sua plena realidade, decide irrevogavelmente a preponderância do Estado, ainda que ela possa apenas assegurar à Igreja a universalidade que lhe convém. [...] A sociedade religiosa é sobretudo destinada a consolidar e desenvolver a sociedade civil, como esta a sociedade doméstica. [...]

Assim, a sociedade religiosa não deve destinar sua universalidade característica senão a completar a sociedade política, ligando entre si as diversas cidades, após sua comum subordinação à Humanidade. Mas a extensão superior da Igreja não a autoriza jamais a considerar-se como representando melhor o verdadeiro Grande Ser que o que fazem os estados ou mesmo as famílias" (COMTE, 1890a, p. 341-344; negrito no original; sem itálicos no original).

O trecho acima, portanto, enseja duas séries de observações. A primeira relaciona-se à prevalência de um poder sobre o outro, ou, como resumiu Bobbio (1997, p. 114-116), ao problema da primazia da política sobre a moral. No pensamento de Augusto Comte não há, no sentido por assim dizer clássico, uma efetiva "primazia" de um poder sobre o outro. Como as considerações práticas guiam o ser humano, mesmo se impondo quando 
são descuradas, é a esfera prática da vida que deve preponderar sobre a intelectual e a afetiva: a cidade e o Poder Temporal preponderam sobre a Igreja e a família, isto é, sobre o Poder Espiritual. Contudo, a "preponderância" não é sinônima de "dominação" ou "submissão": os dois poderes são separados para cada um ter sua liberdade e seu campo de atuação próprio. Assim, se o cidadão - e sob esse título devem ser percebidos todos os seres humanos, todos os servidores da Humanidade deve fidelidade à cidade, deve, por outro lado, ouvir os conselhos e os ensinamentos da Igreja, além de seguir os sentimentos desenvolvidos no seio familiar. Se considerarmos, também, que o Poder Espiritual tem a função de legitimar o Poder Temporal, alem de fiscalizá-lo, torna-se claro que a relação entre ambos não é de submissão, mas de divisão do trabalho. A fórmula comteana para isso era: "a política deve submeter-se à moral".

A segunda observação é de cunho epistemológico: contrariamente ao que uma interpretação estritamente intelectualizante do pensamento comteano poderia sugerir, a realidade prática - os fatores materiais - têm uma importância marcada no Positivismo e em sua percepção da realidade. Aliás, como notou há vários anos Rodolfo Paula Lopes, "Antes do marxismo, o Positivismo proclama que a infra-estrutura determina a superestrutura, ou, em sua linguagem, que os fenômenos intelectuais e sociais subordinam-se às condições materiais e econômicas, mas [...] que é sobretudo pela renovação da super-estrutura que ocorre, no fundo, o progresso" (LOPES, 1946, p. XVII). Em outras palavras, diríamos que se trata apenas de condicionamento do econômico sobre o intelectual e o social, ao invés de determinação ${ }^{19}$.

\section{CONSIDERAÇÕES FINAIS}

O presente texto teve por objetivo apresentar o que atualmente chamamos de "Estado", de acordo com o pensamento de Augusto Comte. Como vimos, esse conceito, bastante contemporâneo no

19 Os fatores materiais, ao exercerem uma pressão condicionante sobre o conjunto da sociedade, tanto em um momento qualquer quanto ao longo da história humana, evidentemente não impedem a validade da lei dos três estados, porque, por um lado, os meros fatores materiais exercem um papel muito mais limitante que, por assim dizer, "propositivo": a base material não cria modos de pensar seus; por outro lado, como vimos na seção II.1 deste artigo, os três estados referem-se a métodos de raciocinar significado geralmente a ele atribuído, foi caracterizado e discutido pelo pensador de Montpellier por meio de duas outras categorias: a pátria e o Poder Temporal. A primeira é um "órgão" da Humanidade, isto é, sua base física, constituída pela união de diversas famílias, organizadas em classes ou castas a partir da divisão social do trabalho, com vistas a prover a base material e prática da sociedade.

O conceito que vincula as pátrias ao Poder Temporal é o princípio de Aristóteles, da separação dos ofícios e da convergência dos esforços: a divisão do trabalho acarreta naturalmente a especialização e, conseqüência também natural embora maléfica, o particularismo. A fim de garantir a convergência dos esforços é necessário o governo - material, para forçar à convergência se necessário e dirigir a atividade dos órgãos convergentes, e espiritual, que garante as vistas do conjunto social, educa os cidadãos e fiscaliza a atuação do poder material.

A análise dos dois poderes, especialmente de suas relações, constitui a parte mais densa e mais interessante do pensamento propriamente político de Augusto Comte, pois é na atuação complementar mas autônoma de um frente ao outro que se constituem e instituem as diversas liberdades sociais.

A preocupação de Augusto Comte era permitir que cada capacidade humana se desenvolvesse plenamente, dentro de sua esfera de ação; além dessa esfera, cada instituição torna-se opressiva, ao invadir o campo de atuação de outras. Cada instituição é complementar às outras, sua harmonia sendo possível a partir daí (ao invés, por exemplo, da juridicamente decretada "harmonia entre os três poderes" de Montesquieu).

Como afirmamos no início deste artigo, as elaborações comteanas são bastante abstratas e integrantes de uma totalidade teórica e não foi nos-

e de interpretar a realidade (COMTE, 1972b): ao longo da história, é como se a base material fosse uma pressão cujo valor é constante, variando a partir dela os modos de conceber a realidade. Em relação estreita com a lei dos três estados intelectuais, ainda que a ela subordinada, está a lei dos três estados da atividade prática: a atividade é primeiramente militar conquistadora (Antigüidade), depois militar defensiva (Idade Média) e por fim pacífica e industrial (modernidade). (Sobre as diversas relações que estabelecem entre si os elementos do sistema comteano, há algumas indicações em Marietti (2003).) 
so objetivo explorar suas conseqüências práticas. A despeito disso, não é difícil perceber-se como as indicações teóricas de Augusto Comte podem ser instrumentalizadas para a prática científica ou, mais simplesmente, para a prática política ou social: a separação entre a Igreja e o Estado, a primazia da moral sobre a política, a necessária possibilidade de crítica do poder Espiritual sobre o Temporal. Esses, porém, são temas para outros artigos.

Gustavo Biscaia de Lacerda (gustavobiscaia@yahoo.com.br)é Mestre em Sociologia Política pela Universidade Federal do Paraná (UFPR) e sociólogo da mesma instituição.

\section{REFERÊNCIAS BIBLIOGRÁFICAS}

ARNAUD, P. 1965. Politique d'Auguste Comte. Paris : A. Colin.

ARON, R. 1999. As etapas do pensamento sociológico. $3^{\mathrm{a}}$ ed. Lisboa: Dom Quixote.

BOBBIO, N. 1997. Estado, gobierno y sociedad: por una teoría general de la política. $2^{\mathrm{a}}$ ed. Ciudad de México : Fondo de Cultura Económica.

BOURDET, E. 1875. Vocabulaire des principaux termes de la Philosophie Positive. Paris : G. Baillière.

COMTE, A. 1890a. Système de politique positive ou traité de Sociologie instituant la Religion de l'Humanité. T.II : Contenant la Statique Sociale ou le Traité abstrait de l'ordre humain. $3^{\text {ème }}$ ed. Paris : Larousse.

.1890b. Système de politique positive ou traité de Sociologie instituant la Religion de l'Humanité. T.III : Contenant la Dynamique Sociale ou le Traité Général du progrès humain. $3^{\text {ème }}$ ed. Paris : Larousse.

1934. Catecismo positivista, ou sumária apresentação da Religião universal. 4 ${ }^{\mathrm{a}}$ ed. Rio de Janeiro : Apostolado Positivista do Brasil.

1957. A General View of Positivism. New York : R. Speller.

. 1972a. Opúsculos de filosofia social. São Paulo : USP.

. 1972b. Considerações filosóficas sobre as ciências e os cientistas. In : . Opúsculos de filosofia social. São Paulo : USP.

1995. Augusto Comte. Los fundamentos de la sociología. Org. Kenneth Thompson. Ciudad de México : Fondo de Cultura Económica.
DESTEFANIS, G. L. 2003. A ordem política e social em Augusto Comte. Curitiba : Vila do Príncipe.

DUMONT, L. 2000. Homo cequalis. Gênese e plenitude da ideologia econômica. Bauru : USC.

DUROSELLE, J.-B. 2000. Todo império perecerá. Teoria das relações internacionais. Brasília : UNB.

FLETCHER, R. 1981. Comte and Marx. In : COMTE, A. Correspondance générale et confessions. T. IV : 1846-1848. Paris : J. Vrin.

HOBSBAWM, E. 1999. Era dos extremos. O breve século XX - 1914-1991. São Paulo : Cia. das Letras.

LACERDA, G. B. 2003. Prefácio : A república positivista : um projeto radical de liberdade e fraternidade. In : LACERDA NETO, A. V. $A$ república positivista. Teoria e ação no pensamento político de Augusto Comte. $3^{\text {a }}$ ed. Curitiba : Juruá.

LACERDA NETO, A. V. 2003. A república positivista. Teoria e ação no pensamento político de Augusto Comte. $3^{\text {a }}$ ed. Curitiba : Juruá.

LACROIX, J. 2003. A Sociologia de Augusto Comte (O fundador da Sociologia). Curitiba : Vila do Príncipe.

LAGARRIGUE, L. 1920. Incorporación del Proletariado a la sociedad moderna. Santiago de Chile : Universo.

LAUBIER, J. (org.). 1957. Auguste Comte. Sociologie. Paris : PUF.

LOPES, R. P. (org.). 1946. Auguste Comte. Le Prolétariat dans la société moderne. Coll. "Archives positivistes". Paris : s/n. 
1981. Auguste Comte et la lutte de classes. In : COMTE, A. Correspondance générale et confessions. T. IV : 1846-1848. Paris : J. Vrin.

MARIETTI, A. K. 2000. Comte ou une science politique conçue comme science de la consistance agrégative. Vérsion révisée de l'article paru dans Les Études Philosophiques, Paris, v. 3, 1974. Disponível em : http://dogma-free.fr. Acesso em : 1.jun.2000.

2003. Épistemologie et politique positives. In : HAAC, G. Hommage à Oscar Haac. Paris : L'Harmattan. Disponível em : http:// $\mathrm{d}$ o g m a.f $\mathrm{r}$ e e.f $\mathrm{r} / \mathrm{t} \times \mathrm{t} /$ AKM_ComptePolitiquePositive.htm. Acesso em : 16.jun.2003.

MARVIN, F. S. 1941. Comte. Ciudad de México : Fondo de Cultura Económica.
MIGUEL, L. F. 2000. Um ponto cego nas teorias da democracia : os meios de comunicação. $B I B$, Rio de Janeiro, n. 49, p. 51-77, $1^{\circ}$ semestre.

ROSSI, P. 1996. Naufrágios sem espectador : a idéia de progresso. São Paulo : UNESP.

SARTORI, G. 1994. A teoria da democracia revisitada. V. I : O debate contemporâneo; v. II : As questões clássicas. São Paulo : Ática.

TORRES, A. 1997. O léxico de Augusto Comte. Criptografia e filosofia. Rio de Janeiro. Dissertação (Mestrado em Filosofia). Universidade Estadual do Rio de Janeiro.

WEBER, M. 1997. Economía y sociedad. Esbozo de una Sociología comprensiva. $2^{\mathrm{a}}$ ed. Ciudad de México : Fondo de Cultura Económica. 